\title{
Transtornos do Espectro Autista e sexualidade: um relato de caso na perspectiva do cuidador
} Trastorno del Espectro Autista y la sexualidad: una presentación de caso en la perspectiva del cuidador

\section{Autism Spectrum Disorders and sexuality: a report from caregivers' perspective}

\author{
Rafael De Tilio \\ Universidade Federal do Triângulo Mineiro, Brasil
}

Autor referente: rafaeldetilio.uftm@gmail.com

Historia Editorial

Recibido: 26/02/2016

Aceptado: 21/4/2017

\section{RESUMO}

Os transtornos espectro autista (TEA) são um grupo de transtornos do neurodesenvolvimento que afetam a interação social e a comunicação. A rotina e dinâmica familiar dos portadores de TEA são afetadas e, por vezes, seus familiares/cuidadores não reconhecem suas possibilidades de desenvolvimento (biológico e psicológico, incluindo sua sexualidade) que passa a ser infantilizado, negado ou rechaçado. O objetivo desta pesquisa foi investigar como uma cuidadora significa a sua vivência da sexualidade de um indivíduo com TEA. Os dados foram obtidos por meio de uma entrevista semiestruturada, gravada e transcrita na íntegra com a irmã cuidadora de um adulto de 35 anos diagnosticado há menos de uma década. Após análise de conteúdo temática os resultados mostraram que há aceitação parcial da sexualidade daquele indivíduo pelos familiares (respeito à privacidade e à masturbação) ao mesmo tempo em que há muitos conflitos (vergonha, medo de comportamentos hipersexualizados não adequados em públicos). Além disso, a cuidadora ou familiares não receberam formação especializada sobre cuidados para TEA, aumentando as dificuldades. Neste sentido, e diante dessa tensão, reforça-se a importância de mais ações educativas em cuidados de saúde e educação e de investigações sobre as relações entre sexualidade, família, TEA e cuidados visando à consolidação dos direitos (sexuais e reprodutivos) destes sujeitos.

Palavras-chave: Sexualidade; Autismo; Cuidadores. 


\section{RESUMEN}

Los Trastornos del Espectro Autista (TEA) son un grupo de trastornos del neurodesarrollo que afecta, entre otros aspectos la interacción social y la comunicación. La rutina y dinámica familiar de los portadores de TEA son afectados $y, a$ veces, sus familiares/cuidadores no reconocen sus posibilidades de desarrollo (biológico y psicológico, incluyendo su sexualidad) que pasa a ser infantilizada, negada o rechazada. El objetivo de esta investigación fue pesquisar como un cuidador comprende un individuo con TEA, específicamente en la vivencia de su sexualidad. Los datos fueron obtenidos por medio de una entrevista semiestructurada, gravada y transcripta integralmente con la hermana cuidadora de un adulto de 35 años, diagnosticado a menos de una década.
Después de un análisis de contenido temático los resultados mostraron que hay una aceptación parcial de la sexualidad de aquel individuo por sus familiares (respeto por su privacidad y masturbación) al mismo tiempo en que hay muchos conflictos (vergüenza, miedo de comportamientos hipersexualizados no adecuados en público); mas allá de eso, la cuidadora o familiares no recibieron formación especializada para cuidar de acometidos por TEA, lo que aumenta las dificultades. En este sentido, y delante de esta tención, se refuerza la importancia de más acciones educativas en cuidados en salud $y$ educación y de investigaciones entre sexualidad, familia, TEA y cuidados que busquen la consolidación de derechos (sexuales y reproductivos) de estos sujetos.

Palabras clave: Sexualidad; Autismo; Cuidadores.

\section{ABSTRACT}

Autism spectrum disorder (ASD) is a behavioral syndrome that affects social interaction and communication. The routine and family dynamics is directly affected when an individual receives a diagnosis of ASD. Sometimes family members/caregivers do not recognize their development possibilities (biological and psychological), including their sexuality, which becomes childlike, denied or rejected. The objective of this research was to investigate representations of one caregiver about the sexuality of an individual diagnosed with ASD. Data were obtained through a semistructured interview with one caregiver (the sister) of an adult diagnosed less than a decade. After thematic content analysis of the interview the highlights results are: that there is partial acceptance of the sexuality by the family (respect for private masturbation) while there are many conflicts (shame, fear of public desappropriate sexualized behavior). At last, there is importance more researches into the relations between sexuality, family, ASD and care towards rights and sexual health practices for these individual.

Keywords: Sexuality; Caregivers; Autism. 


\section{Transtornos do Espectro Autista e Sexualidade}

á tempos a sexualidade tem sido considerada um dos aspectos fundamentais para a constituição da identidade dos indivíduos. Para Mottier (2011) sexualidade compreende as maneiras pelas quais as pessoas vivenciam seus corpos, prazeres e desejos a partir de determinadas orientações sociais.

Apesar de a sexualidade ser vivenciada desde a infância (Calligaris, 2009) é na adolescência que ela será resignificada pelos indivíduos (Calligaris, 2009; Cano \& Ferriani, 2000). Ainda segundo estes autores além das transformações físicas na adolescência ocorrem alterações psicológicas (luto pelo corpo infantil, pressões por maiores responsabilidades e aquisição de autonomia dentre outros) que podem ocasionar inseguranças e conflitos que não raro impactuam a sexualidade.

Para Sousa, Fernandes e Barroso (2006) as dificuldades de pais e filhos dialogarem sobre sexualidade é resultado de situações contemporâneas, tais como os comportamentos de riscos nas relações sexuais por parte dos adolescentes, a precocidade das relações sexuais (tanto por homens quanto por mulheres) e a perpetuação de mitos e tabus concernentes à sexualidade.

Considerando que a família é uma rede de relações, afetos, sentimentos, ações e experiências transmitidas via socialização (Santos \& Ghazzi, 2012) as representações e práticas que uma geração possui sobre sexualidade influenciam as das posteriores. Neste sentido, a família pode ser compreendida como uma instituição de significativa importância para orientar os relacionamentos pessoais e sociais.

Especificamente no caso de famílias com portadores de necessidades especiais de quaisquer espécies Bourgondiera, Reichle e Palmer (1997) e Sprovieri e Assumpção (2001) destacam as dificuldades em lidar com a sexualidade. Para os autores e para Andrade e Teodoro (2012) a dinâmica de relacionamentos e afetos destas famílias são afetadas quando um dos seus integrantes apresenta alguma doença, transtorno ou 
disfuncionalidade. Para Sprovieri e Assumpção (2001) quando ocorrem doenças, transtornos ou disfuncionalidades as famílias geralmente rompem com suas habituais atividades sociais para que o acometido se adapte às especificidades impostas pela disfunção.

Especificamente, os transtornos do espectro autista (TEA) são transtornos invasivos do desenvolvimento caracterizados por déficits na interação social e na comunicação, apresentando repertório de atividades e interesses repetitivos e estereotipados que podem estar acompanhados de problemas cognitivos que podem variar em grau (Backes, Zanon, \& Bosa, 2013). Para Gadia e Rotta (2016) os TEA são parte de um grupo de distúrbios da socialização com início precoce na infância e geralmente possuem desenvolvimento crônico.

Segundo Felipe (2009) e Serra (2010) atualmente a sexualidade dos acometidos por TEA é reconhecida, porém com limitações. Esse parece ser um padrão geral de significação da sexualidade de pessoas com deficiências ou necessidades especiais (Giami, 2004). Para Felipe (2009) o desenvolvimento sexual considerado normal teria a seguinte sequência: até os dois anos ocorrem descobertas das áreas de prazer do corpo; entre dois e cinco anos inicia-se o interesse pelo próprio corpo e de outrem e há a descoberta da diferença sexual entre homens e mulheres, além da exploração do próprio corpo (masturbação) e do corpo de terceiros; a partir dos seis até os 12 anos o autoerotismo tende a diminuir e o heteroerotismo se acentua preparando para a sexualidade genital.

Em suma, a constituição da sexualidade passa da descoberta do próprio corpo para a interação com o outro. Portanto, a socialização e a interação são preponderantes neste processo por balizarem o acesso e a vivência da sexualidade. Dessa forma, dificuldades no desenvolvimento/estabelecimento das interações sociais (como ocorre nos TEA) potencialmente influenciam e prejudicam o desenvolvimento e vivência da sexualidade (Bourgondiera et al., 1997; Felipe, 2009). 
Para Bosa e Zanon (2016) devido às dificuldades nas interações sociais os acometidos por TEA têm o desenvolvimento da sexualidade afetado, que pode ser negada ou infantilizada por parte dos familiares/cuidadores negação. De maneira geral o que a família, cuidadores e sociedade esperam da sexualidade de pessoas portadoras de necessidades especiais é que ela ou não se manifeste ou que ela se apresente inadequada e carente de controle (Bosa \& Zanon, 2016).

Portanto, a sexualidade dos acometidos por TEA pode gerar vários conflitos, pois enquanto eles consideram suas vivências sexuais aceitáveis as demais pessoas (incluindo seus familiares) tendem a considerá-las inadequadas (Bosa \& Zanon, 2016; Felipe, 2009). Todavia, esse último aspecto contraria as atuais políticas públicas internacionais de garantias dos direitos sexuais e reprodutivos das pessoas com algum tipo de deficiência (Gesser \& Nuernberg, 2014) ainda mais quando elas representam $15 \%$ da população mundial.

Assim, quando reconhecida é esperada que a sexualidade dos acometidos por TEA se manifeste de maneira privativa e nominalmente por meio da masturbação individual e não por meio de inadequações como o toque dos genitais em locais públicos e em situações inapropriadas e/ou utilização de palavras e gestos obscenos (Bourgondiera et al., 1997; Felipe, 2009).

Em suma, mesmo que sexualidade dos portadores de deficiências venha sendo enfatizada nos últimos anos ela ainda é repleta de tabus, mitos, equívocos e discriminações. Ademais, as investigações deste tema junto aos cuidadores ou aos acometidos também são poucas e necessitam serem adensadas (Gesser \& Nuernberg, 2014). Devido as dificuldade e limitações em coletar dados diretamente com os acometidos por TEA (o que seria mais apropriado, porém dificultado devido às suas restrições de interação social e cognitivas) informações sobre sua sexualidade podem ser obtidas junto aos seus cuidadores (Gomes, Lima, Bueno, Araújo, \& Souza, 2015). Ademais, há de se considerar que os cuidadores de pessoas acometidas por 
TEA apesar das dificuldades e percalços que enfrentam (devido à elevada carga de trabalho a qual estão submetidos) são fontes significativas para obtenção de informações por manterem contato constante e duradouro com eles (Misquiatti, Brito, Ferreira, \& Assumpção Júnior, 2015), o que justificaria essa opção metodológica.

Desta forma, o objetivo desta pesquisa foi investigar como um cuidador significa um indivíduo com TEA, especificamente sua vivência da sexualidade.

\section{Percurso metodológico}

Trata-se de uma pesquisa qualitativa e descritiva sobre um relato de caso exploratório com uma cuidadora (irmã) de um adulto diagnosticado com TEA.

Pretendendo obter participantes que pudessem conceder entrevistas para essa pesquisa o pesquisador entrou em contato com uma instituição que fornece cuidados em saúde e educação para pessoas acometidas por TEA e outros transtornos invasivos do comportamento. Essa instituição situa-se numa cidade de médio porte da região do Triângulo Mineiro no Estado de Minas Gerais (Brasil).

A instituição em questão é de caráter filantrópico que almeja o desenvolvimento e o bem-estar tanto das pessoas portadoras de deficiências, transtornos e limitações quanto de seus familiares/cuidadores. Seu propósito é possibilitar aos usuários inserção social de acordo com suas necessidades e possibilidades a partir de intervenções direcionadas e específicas.

O pesquisador entrou em contato com o diretor daquela instituição explicitando os objetivos da pesquisa e solicitou a indicação de acometidos por TEA. Tal pedido foi negado cujas justificativas foram pautadas em aspectos éticos e metodológicos (são menores de idade e com comprometimentos cognitivos ou de interação social que inviabilizariam o acesso à amostra e a coleta dos dados). Diante disso, foi proposto 
que indicasse nomes de cuidadores de indivíduos com TEA, o que foi prontamente aceito pela direção da instituição.

O pesquisador contatou as três indicações que lhes foram concedidas (correspondente ao número de cuidadores de indivíduos acometidos por TEA naquela instituição), mas apenas uma delas aceitou participar da pesquisa. Trata-se, portanto, de uma amostra de conveniência.

A coleta de dados ocorreu por meio de uma entrevista semiestruturada realizada em duas sessões com uma cuidadora de acometido por TEA que abordou os seguintes temas: as dificuldades na aceitação do diagnóstico de autismo pelos familiares e pela cuidadora; as principais preocupações com o acometido; suas percepções e as dos demais familiares sobre a sexualidade do acometido; as principais preocupações dos familiares e da cuidadora acerca da sexualidade do acometido (Roteiro para entrevista semiestruturada, 2014).

A entrevista ocorreu em 2014 após aprovação da pesquisa pelo Comitê Local de Ética em Pesquisa da universidade a qual o pesquisador está vinculado (Protocolo Plataforma Brasil 77.862 de 31/07/2014). Foi apresentado o termo de Consentimento Livre e Esclarecido à participante que concordou com as condições da pesquisa. Cada sessão de entrevista teve duração aproximada de uma hora.

Esse procedimento de coleta de dados pode ser designado de relato de caso (Yin, 2010) cujo propósito é compreender um fenômeno em seu contexto específico. Não se trata, portanto, de um estudo de caso exaustivo com utilização de diversificadas fontes de informação, mas sim de uma investigação de caráter exploratório.

A entrevista foi audiogravada e transcrita na íntegra para uma análise de conteúdo temática, realizada a partir da proposta de Bardin (2010).

\section{Resultados e Discussão}


A apresentação dos dados está organizada da seguinte maneira: (i) um breve relato do caso; (ii) as categorias temáticas construídas após a coleta de dados. As categorias temáticas correspondem aos principais temas abordados na entrevista e são as seguintes: diagnóstico (percepção do estabelecimento do diagnóstico; mudanças na rotina familiar após o diagnóstico; dificuldades na aceitação do diagnóstico); sexualidade (sentimentos e percepções da cuidadora acerca da sexualidade do portador de TEA; preocupações dos pais e familiares acerca da sexualidade do filho/irmão; vivências familiares relacionadas ao exercício da higiene pessoal, privacidade e comportamentos sexuais do portador de TEA); ações da instituição (percepção do trabalho realizado com o irmão e capacitação da cuidadora).

É importante reiterar que o escopo dessa pesquisa é a sexualidade do acometido por TEA, mas para compreender melhor essa temática neste relato foi necessário também compreender os processos de diagnóstico e de intervenções ofertadas a esse sujeito.

\section{Relato do caso}

L. (o nome real do acometido foi substituto por essa inicial) tem 35 anos de idade e é o filho mais velho dentre quatro irmãos (três homens e uma mulher) e segundo a cuidadora (que é sua irmã e possui 30 anos) nasceu sem apresentar qualquer comprometimento aparente.

Sua família de origem (pai e mãe) possui formação educacional de nível superior e condição financeira médio-alta. São profissionais liberais autônomos com renda e casa própria que Ihes fornece relativo conforto. Todos os irmãos de L. também são profissionais liberais autônomos financeiramente e independentes que, exceto a irmã cuidadora, não residem com os pais. A irmã-cuidadora de L. justifica que devido às condições particulares de L. seria impraticável ela não residir na mesma casa que ele. Segundo a cuidadora aos três anos de idade L. começou a frequentar a escola regular, momento no qual as professores relataram que ele começou a dar sinais de 
atrasos cognitivos (não acompanhamento das atividades pedagógicas) e dificuldades de socialização (desinteresse pelas atividades lúdicas e recreativas; isolamento social; mutismo ocasional).

Por isso, quando ele tinha quatro anos de idade a direção da escola recomendou que ele frequentasse uma instituição municipal de caráter filantrópico especializada na educação de crianças com problemas de desenvolvimento e aprendizagem. L. frequenta essa instituição até hoje, ou seja, há praticamente 30 anos. Por isso, apesar de alfabetizado L. não possui comprovação de educação formal de qualquer nível e tampouco renda, trabalho ou moradia própria, sendo dependentes dos pais e da cuidadora.

A cuidadora relata que até aproximadamente sete anos atrás (quando L. tinha 28 anos de idade) apesar de evidentemente ele possuir algum tipo de transtorno mental e ter realizado ao longo da vida inúmeras consultas e exames com diversos profissionais (médicos, psiquiatras, psicólogos, fisioterapeutas e fonoaudiólogos) ninguém havia estabelecido diagnóstico preciso para sua condição. Assim, tardiamente e por iniciativa do psicólogo (recém-contratado) da instituição L. passou por novos exames e investigações e foi diagnosticado como portador de TEA.

Após o diagnóstico a cuidadora destacou significativa mudança (no que se refere às interações sociais) motivadas pelo tratamento direcionado as suas demandas e necessidades. Atualmente, segundo a cuidadora, mesmo diante desses avanços L. não se sente totalmente confortável e confiante para frequentar outros espaços sociais que não aquela instituição, estando sempre acompanhado pela cuidadora nessas ocasiões.

\section{O diagnóstico}

A primeira categoria temática congregou relatos da cuidadora sobre o diagnóstico de autismo (TEA) fornecido ao irmão. Assim, partes do seu relato estão relacionadas às 
percepções e compreensões dos familiares acerca do diagnóstico estabelecido. Relatou a cuidadora que:

(...) o homem [o pai] se choca muito com a questão da deficiência, é como se ele não tivesse conseguido algo, e o sonho do meu pai era ter um filho homem. Então, assim, o filho que ia torcer pelo mesmo time que ele, o filho que ia acompanhar ele nos encontros com os amigos, o filho que ia fazer tudo. Então, veio uma frustração muito grande do meu pai. Então, eu desde muito nova tive que entende e ser esse apoio da minha mãe (Rios \& De Tilio, 2014, 3:10).

A cuidadora destacou as dificuldades por parte do pai em aceitar o diagnóstico do irmão e as limitações doravante impostas à vida social de toda a família. Relatou também que diante dessa limitação e dificuldades do pai em aceitar o diagnóstico do filho ela (a filha mais velha) se viu na obrigação de auxiliar a mãe nos cuidados do irmão, dizendo que foi o suporte do irmão desde sua infância e mesmo antes do diagnóstico ter sido realizado.

A participante relatou que o diagnóstico de TEA do irmão apesar de tardio e de difícil aceitação pelos familiares pelo menos ajudou a organizar as intervenções e auxílios destinados a ele:

(...) onde ele tava não tinha mais avanço, e deve ter mais ou menos isso (seis ou sete anosa atrás) que o diagnóstico foi feito. Não sei precisar bem. Mas quando eu penso na evolução que ele teve é tão grande diante de seis, sete anos, parece muito mais tempo. Isso interferiu no próprio jeito da gente: você começa a perceber que tem alguma coisa... você passa ter uma diretriz (Rios \& De Tilio, 2014, 6:15).

Segunda a cuidadora uma das principais dificuldades anteriores ao diagnóstico do irmão (mesmo sendo evidente que ele possuía algum tipo de problema que influenciava sua conduta e a dinâmica familiar) era a inexistência de um direcionamento do tratamento. Ela destacou o quanto o irmão evoluiu comportamental 
e socialmente após o diagnóstico, resultando em avanços individuais (para o irmão) e coletivos (para os familiares) a partir de um acompanhamento particularizado.

Outro eixo de relatos esteve relacionado à aceitação do diagnóstico por parte dos familiares e suas consequências positivas para a dinâmica familiar. A cuidadora contou que quando L. nasceu houve grande dificuldade por parte dos familiares em lidar com a não efetivação da expectativa de um filho totalmente saudável, mesmo que desejado. As limitações que L. apresentava implicaram significativas mudanças nos planos de toda família:

Então quando ele nasceu todos os irmãos dela [mãe] eram solteiros, então era todo mundo por conta dele, ele era a atração. E foi muito rápido ele manifestar... ele retroceder no desenvolvimento... da minha mãe não saber o que é que vinha, o que ele tinha, então foi muito rápido. Por exemplo, eu não amo a deficiência dele, eu amo ele. Alguns dizem 'ah, é um presente ter um filho deficiente', mas pergunta se pudesse mudar isso todo mundo mudava. Se tem uma mãe gestante você pergunta se quer menino ou menina ela responde que tanto faz e que venha com saúde (Rios \& De Tilio, 2014, 2:00).

Para Sprovieri e Assumpção (2001) tal situação (não cumprimento das expectativas do filho-imaginado e recepção de uma criança com TEA) potencialmente gera na família uma dinâmica de sentimentos similares ao luto, pois é preciso rever e reformular o planejamento familiar visando à adequação às exigências reais. Para Andrade e Teodoro (2012) tal situação gera elevado estresse e ansiedade.

Neste sentido, a cuidadora referiu a importância de um suporte emocional para as famílias que precisam lidar com a frustração e a alteração na rotina visando atender as necessidades do acometido pelo transtorno, mesmo alegando que é melhor receber um diagnóstico do que não receber.

Outro eixo de relatos se referiu às mudanças na rotina da família a partir do diagnóstico e do acompanhamento específico em saúde e educação que o irmão 
passou a receber. A participante relatou que mesmo ansiógeno era mais cômodo para todos os familiares quando o irmão acometido por TEA não desenvolvia suas capacidades ou demonstrava seus interesses - em outras palavras, o quanto era mais fácil manejar e controlar o irmão.

Neste sentido, a participante desvelou uma contradição entre desejo de melhora, avanços do tratamento e mudanças versus o comodismo na manutenção da rotina quando o irmão não tinha autonomia e não fazia questionamentos. Isso indica que, no caso, a expectativa da melhora muitas vezes entra em conflito com as dificuldades em permitir e/ou considerar o desenvolvimento e/ou independência do acometido por TEA. Bosa e Zanon (2016) e Bastos e Deslandes (2012) destacam ser muito comum (porém inconsciente) as famílias significarem os acometidos por TEA como não ativos e incapazes de exercer suas vontades, retratando-os como eternas crianças dependentes que demandam proteção. Uma das respostas da participante pareceu corroborar com esse argumento:

A deficiência causa na gente um misto de sentimentos muito doidos, muito difícil de explicar. Ao mesmo tempo em que você quer a pessoa evoluída, você quer por perto. Você viu ele aqui: é aquele marmanjão de homem, mas ele é meu pequeno, eu não vejo como meu irmão mais velho, é meu irmão mais novo (Rios \& De Tilio, 2014, 13:20).

\section{A sexualidade}

A segunda categoria temática versou especificamente sobre as representações da cuidadora sobre a sexualidade do irmão acometido por TEA. Muitas são as subtemáticas que compõem essa categoria.

Uma delas é referente aos sentimentos da própria participante em relação às expressões e vivências da sexualidade do irmão, visto que ela relatou que os familiares ainda encontram dificuldades em lidar com essa questão. A cuidadora expôs 
a perturbação e incômodo de toda família ao ver L. no papel ativo exercendo sua sexualidade, principalmente por considerá-lo uma eterna criança. Essa infantilização da sexualidade nos TEA é destacada por Bastos e Deslandes (2012) que sugerem ser essa uma estratégia recorrente dos familiares/cuidadores para lidarem com sentimentos e sensações incômodas e angustiantes, minorando a sexualidade do acometido.

Além da negação/depreciação da sexualidade outra estratégia referida pela cuidadora foi a condenação e reprovação moral da sexualidade do irmão. Para a cuidadora isso pode ser evidenciado quando a mãe recrimina L. pelas práticas masturbatórias (denominando-as pejorativamente de porcariadas):

"Eu percebi que minha mãe condenou muito no início porque ele [L.] usava termos [verbalizações das fantasias sexuais] que minha mãe não concordava e falava: 'você tá fazendo porcariada', 'você tá fazendo coisa feia de novo', 'você não pode'” (Rios \& De Tilio, 2014, 27:00).

Neste sentido a recriminação da sexualidade adquire sentido a partir da scientia sexualis (Foucault, 2014) que considera a masturbação não como ato erótico normal, mas sim como desvio de conduta da sexualidade normal (heterossexual e adulto). Todavia, o que não se considera é que muitas vezes (para não dizer na maioria das vezes) os portadores de deficiências têm negado o acesso à sexualidade autoerótica e heteroerótica e são tarjados de não-sexuados ou sexualmente disfuncionais (Gesser \& Nuernberg, 2014).

Outro conjunto de falas da cuidadora se referiu às preocupações parentais relacionadas aos comportamentos sexuais do irmão. Para a cuidadora essas preocupações envolvem porém não se limitam às apontadas por Bosa e Zanon (2016) (relacionadas ao medo de possíveis violências sexuais sofridas ou ocasionadas pelos portadores de transtornos mentais) e incluem o receio de que o irmão se machuque durante a masturbação considerando a intensidade e forma como pratica esses atos. 
Infelizmente, a cuidadora mesmo quando inquirida especificamente sobre esse quesito não forneceu detalhes dizendo sentir vergonha sobre o assunto.

Outra preocupação da cuidadora é a forma como terceiros interpretam as manifestações sexuais do irmão e que porventura venham agredi-lo. Por exemplo, numa situação em que L. olhou fixamente para o decote e partes íntimas de uma mulher num Shopping Center:

E ele não tem o senso de olhar discreto, porque a gente olha, mas a gente é discreto, ele não. Então minha mãe tem muito medo, e eu também, de que isso aconteça com alguém que não entenda e ele possa ser até agredido (Rios \& De Tilio, 2014, 35:20).

No que tange a execução da própria higiene pessoal (incluindo a limpeza da genitália) a cuidadora apontou que o irmão sempre foi estimulado pelo pai para que o fizesse de maneira independente. Ela enfatizou que essa é uma preocupação que partiu do próprio pai desde a infância de L. visando à independência do filho. Assim, ela (cuidadora) auxiliava o irmão em outros âmbitos (alimentação, vestimentas, aprendizagem, acompanhamento nas consultas médicas etc.).

Ao relatar a privacidade sexual que a cuidadora acredita que o irmão possua (por ela compreendida como a privatização da vivência/expressão da sexualidade) ela supõe que foram aprendidas a partir das reiteradas correções e observações efetivadas pelos familiares em situações cotidianas, visto que o irmão nunca recebeu aprendizagem formal sobre educação sexual nas escolas que frequentou.

Isso foi ilustrado pela cuidadora quando relatou um episódio sobre a capacidade de aprendizagem do irmão. Numa ocasião a irmã mais nova explicou a L. a necessidade dele fechar a porta do próprio quarto e/ou bater na porta do quarto dos outros irmãos antes de entrar para preservar a intimidade e privacidade mútua. A participante considerou que isso foi compreendido pelo irmão e aplicado às questões referentes à sexualidade, pois: 
Um dia entrei no quarto dele pouco depois que ele tinha se masturbado, aí ele viu que o lençol estava sujo e tampou com o edredom, rápido. Aí eu percebi que ele tá começando a perceber que isso é particular, que é individual (Rios \& De Tilio, 2014, 25:30).

A principal manifestação aparente da sexualidade do irmão, segundo a cuidadora, é a masturbação. Tal consideração vai ao encontro da literatura científica sobre o assunto que compreende ser isso decorrente das limitações de interação social dos acometidos por TEA - logo as manifestações sexuais serão prioritariamente autoeróticas (Bastos \& Deslandes, 2012).

Por isso foram e são enormes os esforços dos familiares para disciplinar as práticas masturbatórias de L. A cuidadora relatou que percebeu que a excitação sexual do irmão se inicia a partir da visualização de mulheres (na rua, em fotos ou na televisão). Ela diz que se trata de uma excitação total e exclusivamente ligada às mulheres e apenas pela visualização. Sobre esses aspectos Gesser e Nuernberg (2014) tecem interessantes comentários: quando a sexualidade das pessoas com deficiências não é negada geralmente ela é referida como heterossexual pelos familiares como tentativa de diminuir as estigmatizações já existentes devido às suas condições limitantes, pois seria duplamente estimatizante caso o acometido também fosse homossexual.

A cuidadora supõe que a sexualidade de L. seja heterossexual e exclusivamente motivada pela excitação visual porque ele nunca fica sozinho em casa (sempre está acompanhado por um familiar ou por ela) ou na escolar (sempre está acompanhado por um educador). Daí ela acredita que as práticas sexuais do irmão nunca efetivamente envolvem terceiros e estão limitadas à imaginação e à masturbação.

A cuidadora relatou que L. sempre verbaliza as cenas de excitação (que visualiza nas revistas ou que imagina) quando se masturba e/ou simula o ato sexual se esfregando na cama. Na maioria das vezes esses relatos são escutados por todos os familiares: 
Porque a excitação dele se dá falando. E ele vai repetindo alguma cena, ele vai imaginando, vai reproduzindo isso na fala. Isso para a gente é incômodo. E quando começou [anos atrás] era mais [frequente]. A gente conversou que isso se faz é no banheiro, com a porta fechada - pois ele não tinha o cuidado de fechar a porta - então, se faz no quarto é com a porta fechada. Mas ele não tem aquela masturbação normal... o que ele faz: ele se esfrega na cama e fala muito alto (Rios \& De Tilio, 2014, 24:00).

Há uma evidente tentativa por parte da cuidadora e dos familiares em domesticar a sexualidade de L. como se isso fosse suficiente para cumprir com as expectativas e necessidades do próprio irmão e dos familiares. Tal estratégia familiar reitera o relatado por Bourgondiera et al. (1997) e Gesser e Nuernberg (2014): ela é tentativa de controlar a ansiedade e desconhecimento acerca de como lidar com a sexualidade dos acometidos por TEA - quando ela necessitaria ser reconhecida como distinta. Ainda tratando da sexualidade manifestada pelo irmão a cuidadora destacou que L. não exerce ativamente nenhum comportamento sexual fora de seu quarto - exceto os olhares incisivos que lança para as mulheres no espaço público. Ela percebe que essa aprendizagem e compreensão por parte do irmão ocorreu principalmente devido às condenações da mãe para com tais condutas:

Não sei se a partir do momento que minha mãe parou de criticar tanto, ou se justamente porque ela criticou tanto, eu não percebo na mente dele quando isso aconteceu, mas ele já começou a perceber que isso [sexualidade e suas manifestações] é muito individual (Rios \& De Tilio, 2014, 18:50).

Para finalizar essa categoria a cuidadora destacou que o tema sexualidade é um tabu para toda família (e não apenas para com o irmão acometido por TEA) e sempre foi tratado com rigidez. Conforme apontam Santos e Ghazzi (2012) isso pode significar que alguns elementos (no caso, a repressão à sexualidade distribuída pelos 
familiares) podem servir de esteio para práticas socializatórias naquela família (isto é, para todos os membros) e não apenas para L.

As ações educativas em sexualidade

Essa categoria apresenta informações prestadas pela cuidadora relacionadas à participação de L. e dela própria em programas e ou instituições de saúde e educação que contemplem o tema sexualidade.

Quanto à participação em ações/programas de educação sexual a cuidadora apontou que L. nunca participou de algo específico ou especialmente direcionado para esse propósito. Segundo ela L. recebeu ao longo da sua vida apenas orientações difusas sobre sexualidade por parte do psicólogo da instituição educacional que frequenta.

Ela também relatou que apesar de ser a cuidadora prioritária do irmão e ser a sexualidade (e suas manifestações) tema que gera incompreensões, dificuldades e conflitos entre os familiares e L. também nunca participou de capacitações sobre o assunto. Sua justificativa para isso é a inexistência na sua cidade de programas com esse objetivo:

Agora, dúvida eu tenho de como lidar com a sexualidade dele. Falta muita orientação, eu acho que falta na escola um projeto de apoio para os pais. Precisa sentar, precisa conversar, precisa entender como é que cada um faz e vive sua sexualidade. Precisa de um apoio psicológico. Toda a atenção psicológica à pessoa com deficiência intelectual é dirigida ao paciente e pouco para a família que precisa tanto ou mais (Rios \& De Tilio, 2014, 50:00).

Essa fala deixa entrever conforme argumentam Misquiatti et al. (2015) a necessidade de programas que ofereçam suporte e informações especializadas (sobre diversos assuntos) para as famílias de acometidos por TEA. Isso possibilitaria melhores condições (incluindo as emocionais) para lidar com as dificuldades que o transtorno distribui ao indivíduo e sua rede de familiares e cuidadores. 
Ainda para Bastos e Deslandes e (2012) e Misquiatti et al. (2015) a sexualidade dos acometidos por TEA é tema é tema dificultoso para os familiares e cuidadores e justamente por isso as instituições escolares/educacionais destinadas a esses indivíduos deveriam desenvolver ações de auxílio e formação específica tanto para os usuários quanto para seus cuidadores diretos.

Nesse sentido, para a cuidadora é fundamental falar sobre sexualidade, sobre as manifestações de condutas sexuais e até sobre a (in)adequação social e sexual do irmão. Mas ela considera que mesmo sendo isso necessário não é suficiente, pois o acompanhamento dos acometidos por TEA deve ser exercido pelos familiares e pelos educadores num trabalho conjunto entre a casa/família e instituições sociais visando o aumento na qualidade de vida de todos os envolvidos.

\section{Considerações finais}

No relato de caso apresentado o nascimento e, posteriormente, o diagnóstico de um familiar como portador de transtorno do espectro autista (TEA) juntamente com todas as dificuldades apresentadas por essa situação foi muito impactante para os familiares e ocasionou mudanças na rotina familiar.

A dificuldade e demora do diagnóstico (apenas realizado na vida adulta daquele sujeito), o não direcionamento do tratamento e a falta de informações especializadas implicaram em problemas e dificuldades no enfrentamento dessa condição e potencializaram desconfortos na rotina e dinâmica familiar que incluem, porém ultrapassam a sexualidade.

No que se refere especificamente à sexualidade do acometido por TEA a cuidadora participante desta pesquisa relatou que em consonância com a literatura da área a principal manifestação do acometido é a masturbação. Talvez isso ocorra devido às 
limitações socializatórias que os próprios familiares e cuidadores impõem a esses indivíduos, acentuando (quando não ocasionando) o isolamento social.

Percebeu-se a partir do relato da participante o evidente desconforto dos familiares ao tratar da sexualidade do acometido por TEA apesar das tentativas de aceitação e normatização da sexualidade do autista. Todavia, é importante considerar que naquela dinâmica familiar a sexualidade se apresenta como tabu para todos os envolvidos, não apenas para L.

A participante considerou que sua família significa o acometido por TEA como uma eterna criança ou dependente: os familiares esperam que ele seja ou dessexualizado ou que sua sexualidade seja domesticada, acentuando as dificuldades em lidar com esse assunto - o que está de acordo com a literatura da área.

Todavia, tais concepções apresentam importantes consequências aos acometidos por TEA. Considerando a dificuldade de percepção de que se o acometido é um indivíduo que se desenvolve (biológica e sexualmente) de maneira específica, porém não anormal, a família resiste em aceitar que se trata de um sujeito possuidor de direitos, desejos e manifestações sexuais - o que não corrobora para com a plena autonomia deste(s) sujeito(s).

O tema sexualidade é um assunto tabu em vários contextos. Porém, tratar desse tema relacionado às pessoas com algum tipo de deficiência, limitação ou necessidade especial é ainda mais complexo, porém fundamental para questionar equívocos, mitos e exclusões.

Por isso é importante que o tema seja discutido considerando a efetiva possibilidade de manifestação e vivência da sexualidade por partes dos acometidos por TEA, contribuindo, assim, para a melhora da sua qualidade de vida. Ficou evidente também a necessidade de um acompanhamento para os familiares e cuidadores para que sejam capacitados e oportunizem o desenvolvimento integral daqueles que requerem atenção e demandas diferenciadas. 
Apesar das limitações dessa investigação (relato de caso exploratório) suas potenciais contribuições devem ser consideradas. Dessa maneira, o objetivo desta pesquisa (investigar como um cuidador significa um indivíduo com TEA, especificamente a sua vivência da sexualidade) foi alcançado.

Por fim e considerando os limites e contribuições dessa investigação conclui-se que há uma premente necessidade de outras pesquisas sobre o tema visando esclarecer as dificuldades em torno da dinâmica familiar de cuidados e atenção de pessoas acometidas por TEA. Isso poderia auxiliar a diminuir o desconforto e problemas relacionados à sexualidade dos mesmos.

Evidencia-se ainda a importância de estabelecer programas educacionais e de saúde sobre sexualidade tanto para os familiares e cuidadores como para os acometidos por TEA de acordo com suas capacidades e necessidades. Apenas assim poder-se-á observar e garantir seus direitos e desejos sexuais e reprodutivos, tema importante para a saúde do indivíduo e da sociedade. 


\section{Referências}

Andrade, A. A., \& Teodoro, M. L. M. (2012). Família e autismo: Uma revisão da $\begin{array}{llll}\text { literatura. } & \text { Contextos } & \text { Clínicos, } & \text { 5(2), }\end{array}$ doi:http://dx.doi.org/10.4013/ctc.2012.52.07

Backes, B., Zanon, B., \& Bosa, C. A. (2013). A relação entre regressão da linguagem e desenvolvimento sociocomunicativo de crianças com transtorno do espectro do autismo. CoDAS, 25(3), 268-273. doi:https://dx.doi.org/10.1590/S231717822013000300013

Bardin, L. (2010). Análise de conteúdo. Lisboa: Edições 70.

Bastos, O. M., \& Deslandes, S. F. (2012). Sexualidade e deficiência intelectual: Narrativas de pais de adolescentes. Physis: Revista de Saúde Coletiva, 22(3), 1031-1046. doi:http://dx.doi.org/10.1590/S0103-73312012000300010

Bosa, C. A., \& Zanon, R. (2016). Autismo: Vivências e caminhos. Em V. L. Caminha, Assis, J. H. L. M., \& P. P. Alves (Orgs.), Bases teóricas do desenvolvimento pré-linguístico: Implicações para o diagnóstico precoce do autismo (pp. 33-44). São Paulo: Blucher.

Bourgondiera, M. E. V., Reichle, N. C., \& Palmer, A. (1997). Comportamento sexual em adultos com autismo. Journal of Autism and Developmental Disorders, 27(2), 15-17.

Calligaris, C. (2009). Adolescência. São Paulo: PubliFolha.

Cano, M. A. T., \& Ferriani, M. das G. C. (2000). Sexualidade na adolescência: Um estudo bibliográfico. Revista Latinoamericana de Enfermagem, 8(2): 18-24. doi:http://dx.doi.org/10.1590/S0104-11692000000200004

Felipe, C. N. (2009). A sexualidade na Síndrome de Asperger. Revista Diversidades, 23, 23-26. 
Foucault, M. (2014). História da sexualidade: A vontade de saber. Rio de Janeiro: Paz e Terra.

Gadia, C., \& Rotta, N. T. (2016). Aspectos clínicos do transtorno do espectro autista. Em N. W. Rotta, I. Ohlweiller, \& R. S. Riesgo (Orgs.), Transtornos da aprendizagem: Abordagem neurobiológica e multidisciplinas (pp. 368-377). Porto Alegre: Artmed.

Gesser, M., \& Nuernberg, A. H. (2014). Psicologia, sexualidade e deficiência: Novas perspectivas em direitos humanos. Psicologia, Ciência e Profissão, 34(4), 850863. doi:http://dx.doi.org/10.1590/1982-370000552013

Giami, A. (2004). O anjo e a fera: Sexualidade, deficiência mental, instituição. São Paulo: Casa do Psicólogo.

Gomes, P. T. M., Lima, L. H. L., Bueno, M. K. G., Araújo, L. A., \& Souza, M. N. (2015). Autism in Brazil: A systematic review of family challenges and coping strategies. $\begin{array}{llll}\text { Jornal de } & \text { Pediatria, } & \text { 91(2), } & \text { 11-121. }\end{array}$ doi:http://dx.doi.org/10.1016/j.jped.2014.08.009

Misquiatti, A. R. N., Brito, M. C., Ferreira, F. T. S., \& Assumpção Júnior, F. P. (2015). Sobrecarga familiar e crianças com transtorno do espectro do autismo: Perspectiva dos cuidadores. Rev. CEFAC, 17(1), 192-200. doi:http://dx.doi.org/10.1590/1982-0216201520413

Mottier, V. (2011). Sexuality: A very short introduction. Oxford: University Press.

Rios, N., \& De Tilio, R. (2014, setembro 30). Entrevista [Arquivo de áudio]. Registro inédito. Departamento de Psicologia, Universidade Federal do Triângulo Mineiro, Uberaba, Brasil.

Roteiro para entrevista semiestruturada. (2014). Recuperado de https://docs.google.com/document/d/11H0IXuAj14Altohpv9w7FD5rExlbGLo2JT_RzSvNul/edit 
Santos, V. O., \& Ghazzi, M. S. (2012). A transmissão psíquica geracional. Psicologia: Ciência e Profissão, 32(3), 632-647. doi:http://dx.doi.org/10.1590/S141498932012000300009

Serra, D. (2010). Autismo, família e inclusão. Polêm!ca, 9(1), 40-56.

Sousa, L. B., Fernandes, J. F. P., \& Barroso, M. G. T. (2006). Sexualidade na adolescência: Análise da influência de fatores culturais presentes no contexto familiar. Acta Paulista de Enfermagem, 19(4), 408-413. doi:http://dx.doi.org/10.1590/S0103-21002006000400007

Sprovieri, M. H. S., \& Assumpção, F. B. (2001). Dinâmica familiar de crianças autistas. Arq. Neuropsiquiatria, 59, 230-237. doi:http://dx.doi.org/10.1590/S0004$282 \times 2001000200016$

Yin, R. (2010). Estudo de caso: planejamento e método. Porto Alegre: Bookman.

Formato de citación

De Tilio R. (2017). Transtornos do Espectro Autista e sexualidade: um relato de caso na perspectiva do cuidador. Psicología, Conocimiento y Sociedad, 7(2), 36-58. Disponible en: http://revista.psico.edu.uy/ 